\title{
Effects of exogenous salicylic acid and pH on pathogenicity of biotrophy-associated secreted protein 1 (BAS1)-overexpressing strain, Magnaporthe oryzae
}

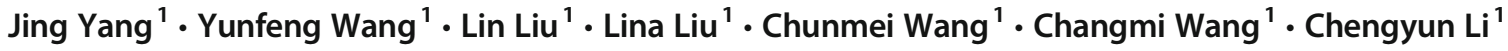

Received: 27 February 2018 / Accepted: 11 June 2018 / Published online: 21 June 2018

(C) The Author(s) 2018

\begin{abstract}
Abiotic stress can influence the interactions between a pathogen and its host. In this paper, we analyzed the effects of salicylic acid (SA) and pH on the morphological development and pathogenicity of Magnaporthe oryzae, the pathogen that causes rice (Oryza sativa) blast. A strain of rice blast that overexpresses biotrophy-associated secreted protein 1 (BAS1) and a wild-type (WT) strain were pretreated with different levels of $\mathrm{pH}$ and different concentrations of SA to analyze $M$. oryzae colony growth, sporulation, spore germination, dry weight of hypha, and appressorium formation. Disease incidence and the expression of defense-related genes in infected rice were analyzed after pretreatment with $\mathrm{pH}$ 5.00 or $\mathrm{pH} 8.00$ and $200 \mu \mathrm{M}$ SA. The results showed that both SA and pH had some influence on morphological development, including sporulation and appressorium formation of the BAS1-overexpression strain. In the $200 \mu \mathrm{M}$ SA pretreatment, there was a lower incidence of disease and higher expression levels of the rice defense-related genes $P R 1 a$, $P A L, H S P 90$, and PR5 on leaves inoculated with the BAS1-overexpession strain compared with the WT strain, whereas, $L O X 2$ appeared to be downregulated in the BAS1-overexpession strain compared with the WT. In both pH treatments, disease incidence and expression of HSP90 were higher and the expression of PRIa and PR10a and LOX2 and PAL was lower in leaves inoculated with the BAS1-overexpression strain compared with leaves inoculated with the WT strain. We conclude that SA and $\mathrm{pH}$ affect morphological development of the BAS1-overexpression blast strain, but that these factors have little influence on the pathogenicity of the strain, indicating that BAS1-overexpression may have enhanced the tolerance of this rice blast strain to abiotic stressors. This work suggests new molecular mechanisms that exogenous $\mathrm{SA}$ and $\mathrm{pH}$ affect the interactions between $M$. oryzae and rice.
\end{abstract}

Keywords Magnaporthe oryzae $\cdot$ Rice $\cdot$ Salicylic acid $\cdot \mathrm{pH} \cdot$ Pathogenesis-related genes $\cdot$ Abiotic stress

$\begin{array}{ll}\text { Abbreviations } \\ \text { AOS2 } & \text { Allene oxide synthase 2 } \\ \text { BAS1 } & \text { Biotrophy-associated secreted protein 1 } \\ \text { CRN } & \text { Crinkling and necrosis induced protein } \\ \text { DMSO } & \text { Dimethyl sulfoxide } \\ \text { EDS1 } & \text { Enhanced disease susceptibility } 1 \\ \text { hpi } & \text { Hours post-inoculation } \\ \text { HSP90 } & \text { Heat shock protein } 90\end{array}$

Responsible editor: Yi-ping Chen

Chengyun $\mathrm{Li}$

zhongdianshiyansh@163.com

$1 \quad$ State Key Laboratory for Conservation and Utilization of Bio-Resources in Yunnan, Yunnan Agricultural University, Kunming, Yunnan, China

$\begin{array}{ll}\text { JA } & \text { Jasmonic acid } \\ \text { LOX2 } & \text { Lipoxygenase 2 } \\ \text { LTH } & \text { Lijiangxintuanheigu } \\ \text { PCD } & \text { Programmed cell death } \\ \text { PDA } & \text { Potato dextrose agar } \\ \text { PDB } & \text { Potato dextrose broth } \\ \text { PSCRN115 } & \text { Phytophthora sojae crinkling and necrosis in- } \\ & \text { duced protein 115 } \\ \text { qRT-PCR } & \text { Quantitative real-time polymerase chain } \\ & \text { reaction } \\ \text { PAL } & \text { Phenylalanine ammonia lyase } \\ \text { PR1a } & \text { Pathogenesis-related 1a } \\ \text { PR5 } & \text { Pathogenesis-related 5 } \\ \text { PR10a } & \text { Pathogenesis-related 10a } \\ \text { SA } & \text { Salicylic acid } \\ \text { WT } & \text { Wild-type }\end{array}$




\section{Introduction}

The effector proteins secreted by plant pathogens play a key role in the interaction between the pathogens and the host plant as well as in the progression of the disease. Effector proteins are considered to manipulate the host's cell structure and function, facilitate infection, and suppress the host's immune response (Kamoun 2006; Hogenhout et al. 2009; Cooper et al. 2016). Once effector proteins enter the host, they can both work in the extracellular matrix and change the host's cellular environment to facilitate infection and colonization (Kamoun 2006; Ridout et al. 2006; Hogenhout et al. 2009; Białas et al. 2017).

Pathogens secrete various enzymes based on their surrounding environment (Gebauer et al. 2017; Gumtow et al. 2017; Kaverinathan et al. 2017). During the infection period of Botryis cinerea, the fungus can secrete various intracellular polygalacturonases to facilitate its infection (Louis et al. 2014). Environmental conditions may also play a role; many studies have reported that temperature and $\mathrm{pH}$ can influence the secretion of effector proteins by pathogens. Louis et al. (2014) found different soluble candidate effector proteins were secreted by Cochliobolus lunatus at different temperature conditions. Some fungi have evolved complicated regulatory mechanisms to recognize and respond to the surrounding $\mathrm{pH}$ changes, such as secreting different proteins according to different $\mathrm{pH}$ levels in the surrounding environment ( $\mathrm{Li}$ et al. 2012). To invade its host successfully, $B$. cinerea can secrete different proteins in different tissues of the host (Sharma et al. 2016). Although some real virulence factors can successfully suppress a host's defense response, they still need to function in coordination with specific extracellular secreted proteins ( $\mathrm{Li}$ et al. 2012). The study on $B$. cinerea shows that the culture solution of $B$. cinerea is black under the conditions of $\mathrm{pH} 4$ and $\mathrm{pH} 6$ because of the secondary metabolites produced during the growth of the hyphae (Sharma et al. 2016; Kaverinathan et al. 2017). A separate study showed that the microenvironment $(\mathrm{pH})$ of the host plant could regulate an arsenal of enzymes to increase fungal pathogenicity (Alkan et al. 2013). Thus, we can conclude that $\mathrm{pH}$ is a major environmental factor that affects the fungus secreting effector proteins and promotes its colonization in the host's tissues. Other studies have shown that the $C$. lunatus isolates with higher melanin levels are more virulent than those with lower melanin levels; thus, melanin and related secondary metabolite are considered to be virulence factors of C. lunatus (Xu et al. 2007; Gao et al. 2012).

M. oryzae (Ascomycotina) cause the fungal disease rice blast, which has serious effects on rice (Oryza sativa) production, severely impairing rice yield and quality. Under normal conditions, conidia that fall on the surface of the host plant start to germinate. Germ tubes quickly differentiate to form specialized infected cells, i.e., the appressoria. M. oryzae have a highly specialized infection structure, an appressorium, which penetrates the host plant (Howard et al. 1991; Jong et al. 1997). After penetrating the host, the invasive hyphae grow rapidly in the host cells and, concurrently, spindle-shape lesions appear. After 5 to 7 days, a large number of conidia are produced on lesions and a new round of the infection cycle begins. During infection, the microenvironment of the host plant cells can change, including the $\mathrm{pH}$, temperature, and humidity around the infection site. The host cells may also increase or decrease levels of hormones, such as salicylic acid (SA) and jasmonate acid (JA), which can affect signal transduction and the production of lysates and secondary metabolites. For example, the expression of the $P R 1$ gene can be induced by SA and JA (Mitsuhara et al. 2008).

There are also many reports about how the signal transduction pathway in fungal cells is related to $\mathrm{pH}$ level. Fungi can grow and develop in a wide range of $\mathrm{pH}$ levels because fungi can regulate their surrounding $\mathrm{pH}$ by secreting acidic or alkaline substances (Piccirillo et al. 2010; Pen et al. 2011; Landraud et al. 2013); these secretions can further facilitate its ability to infect and colonize a host plant. Thus, environmental factors (e.g., temperature, humidity, $\mathrm{pH}$, active oxygen, and $\mathrm{SA}$ ) are predicted to play an important role in the interaction between the $M$. oryzae and its rice host. Therefore, understanding the effects of the environmental factors on the interaction between the M. oryzae and the host could help to reveal new pathogenic mechanisms of $M$. oryzae.

This paper studied the effects of an exogenous hormone (SA) and $\mathrm{pH}$ on the sporulation, spore germination, appressorium formation, and mycelial growth, pathogenicity of a strain of $M$. oryzae that overexpresses biotrophy-associated secreted protein 1 (BAS1). This study aims to provide a platform for further analyses of the effect of abiotic stress on the interaction between the pathogen and its host plant, and provide important theoretical and experimental proofs for guiding the agricultural management.

\section{Materials and methods}

\section{Materials}

The wild-type (WT) strain of M. oryzae (95234I-1b) used here is stored in our laboratory. Strain 35S:BAS1/Mo-2 is a transformed strain that overexpresses BAS1; it is also stored in our laboratory and was obtained by transforming the expression vectors of BAS1 and mCherry fusion under the $35 \mathrm{~S}$ promoter constructed.

Lijiangxintuanheigu (LTH) was used in this paper; the rice variety was a universally susceptible variety, which is also stored in our laboratory. 


\section{Methods}

\section{Culture of blast strain in media containing different concentrations of $\mathrm{SA}$ and different $\mathrm{pH}$ values}

Mycelial pellets of rice blast strain were placed on a PDA (potato dextrose agar) medium, and then put in a $28^{\circ} \mathrm{C}$ incubator for 7 days. The fresh mycelia pellets in PDA were put into a triangular flask filled with potato dextrose broth (PDB) culture medium, and then put the triangular flask in a shaker of $28^{\circ} \mathrm{C}$ and $120 \mathrm{rpm}$ for 3 days of culture. We dissolved the SA (Sigma, MO, USA) in a small amount of dimethyl sulfoxide (DMSO) and prepared the culture media for the different SA concentrations. The control (CK) treatment consisted only of the quantity of DMSO required for preparing the highest SA concentration and an aliquot of sterile water. The six SA treatments were as follows: $50 \mu \mathrm{M}, 100 \mu \mathrm{M}, 200 \mu \mathrm{M}, 500 \mu \mathrm{M}$, $1 \mathrm{mM}$, and $2 \mathrm{mM}$. The $\mathrm{pH}$ was adjusted for each culture media (PDA, PDB), by adding $20 \mathrm{mmol} / \mathrm{L}$ MES buffer solution or $20 \mathrm{mmol} / \mathrm{L}$ MOPS buffer solution and then further adjusted using $\mathrm{NaOH}$ or $\mathrm{HCl}$ (Landraud et al. 2013).

\section{Effects of SA concentration and $\mathrm{pH}$ on the growth of $M$. oryzae mycelium}

We used mycelia pellets with a puncher of $7 \mathrm{~mm}$ in diameter and inoculated them onto PDA media containing different SA concentrations or different $\mathrm{pH}$ values. Pellets were placed in the $28{ }^{\circ} \mathrm{C}$ incubator for culture. We measured the colony diameters on day 10 .

\section{Spore production of $M$. oryzae}

We inoculated $300 \mu \mathrm{L} M$. oryzae culture solution into Ximeizhi media containing different SA concentrations and different $\mathrm{pH}$ levels and then placed them in a $28^{\circ} \mathrm{C}$ incubator for culture for 4 days in the dark, followed by alternate light and darkness (12:12, dark:light) for 6 days. We washed the cultured M. oryzae spores with $5 \mathrm{~mL}$ sterile water and filtered them with gauze. The filtered solution was mixed uniformly and the spores were counted with a blood-counting chamber.

\section{Observation of spore germination and appressorium formation in M. oryzae}

We adjusted the sterile water containing buffer solution into an aqueous solution of different $\mathrm{pH}$ values with $\mathrm{NaOH}$ and $\mathrm{HCl}$. We collected the spores of $M$. oryzae from Ximeizhi media. SA solution was added to adjust the spore concentration to $1 \times 10^{5}$ spores $/ \mathrm{mL}$. We then took $10 \mu \mathrm{L}$ of the spore suspension and added it to a hydrophobic slide, and placed the slide in a $28^{\circ} \mathrm{C}$ constant-temperature petri dish. We observed spore germination after $2 \mathrm{~h}$ and appressorium formation after $6 \mathrm{~h}$.

\section{Culture and inoculation of rice seedlings}

Rice seeds were sterilized for about $1 \mathrm{~min}$ in hypochlorite before sowing. Seeds of LTH were soaked in sterilized water and placed into a $28{ }^{\circ} \mathrm{C}$ constant-temperature incubator until dehiscent, and then sown into a seedling bed. Rice seedlings were used for the inoculation experiments when they had formed three leaves (approximately 20 days). To prepare the $M$. oryzae inoculum, we washed the $M$. oryzae spores with sterile water, centrifuged them for about $1 \mathrm{~min}$ and discarded the supernatant. Next, we added sterile aqueous solutions of $\mathrm{pH} 5.00, \mathrm{pH} 8.00$, or CK (sterile water), and SA solutions of $200 \mu \mathrm{M}$ with CK (DMSO solution required in $200 \mu \mathrm{M} \mathrm{SA}$ ), to adjust the spore suspension to a concentration of $1 \times 10^{5}$ spores $/ \mathrm{mL}$, and added in $0.02 \%$ Tween 20 . The inoculant was applied as a spray to the entire seedlings. Seedlings were kept in the inoculation hood for $24 \mathrm{~h}$ after inoculation to preserve the heat and humidity in the darkness after which they were transferred to the greenhouse. About 15 leaves were taken for quantitative analysis $0,24,48,72,96$, and $120 \mathrm{~h}$ after the spray inoculation. Seven days after inoculation, we performed a disease investigation. Disease incidence rate was calculated as the number of infected leaves divided by the total number of leaves.

\section{Total RNA extraction, cDNA reverse transcription, and qRT-PCR}

Total RNA was extracted with RNA extraction kit: Eastepr ${ }^{\circledR}$ Super Total RNA Extraction Kit LS1040 (Promega, WI, USA), following the manufacturer's instructions. Complementary DNA (cDNA) reverse transcription was done with a reverse transcription kit: GoScriptTM Reverse Transcription System A5001 (Promega), following the manufacturer's instructions. For quantitative real-time PCR (qRT-PCR) of the target gene, we used primer designs modified from the literature (Marce et al. 2010). The primer sequence is shown in Table 1; actin gene was control. Preparation of $20 \mu \mathrm{L}$ qRT-PCR reaction system: cDNA of $4 \mu \mathrm{L}$, RNA-free water of $5.2 \mu \mathrm{L}$, forward and reverse primer of $0.4 \mu \mathrm{L}$, respectively, SYBR Premix Ex Taq II (Takara, Tokyo, Japan) of $10 \mu \mathrm{L}$. The qRT-PC reaction conditions were as follows: (1) denaturation at $95{ }^{\circ} \mathrm{C}$ for $3 \mathrm{~min}$; (2) denaturation at $95^{\circ} \mathrm{C}$ for $20 \mathrm{~s}$; (3) annealing and extension at $60{ }^{\circ} \mathrm{C}$ for $20 \mathrm{~s}$; (4) collection of fluorescence signal at $65^{\circ} \mathrm{C}$; cycle number of 44 . After the cycling, temperature was adjusted from 60 to $98^{\circ} \mathrm{C}$ to obtain the dissociation curve.

\section{Data analysis method}

For the qRT-PCR data processing and statistical analysis, we used the $2^{-\Delta \Delta \mathrm{Ct}}$ method (Livak and Schmittgen 2001). Three biological replicates and three technical replicates were 
Table 1 Primer sequences of the target genes in rice leaves

\begin{tabular}{|c|c|c|}
\hline Gene & Accession number & Primer pair $\left(5^{\prime} \rightarrow 3^{\prime}\right)$ \\
\hline OsPRIa & Os07g03710 & $\begin{array}{l}\text { F:5'-GCTACGTGTTTATGCATGTATGG-3' } \\
\text { R:5'-TCGGATTTATTCTCACCAGCA-3' }\end{array}$ \\
\hline OsPR10a & Os $12 \mathrm{~g} 36880$ & $\begin{array}{l}\text { F:5'-AATGAGAGCCGCAGAAATGT-3' } \\
\text { R:5'-GGCACATAAACACAACCACAA-3' }\end{array}$ \\
\hline$O s P A L$ & Os02g41680 & $\begin{array}{l}\text { F:5'-TCACAAGCTCAAGCACCATC-3' } \\
\text { R:5'-CTCACCAAGCTTCTTGGCAT-3' }\end{array}$ \\
\hline$O s E D S 1$ & Os09g22450 & $\begin{array}{l}\text { F:5'-AGCTGTGGCAGAAGAGAAGC-3' } \\
\text { R:5'-GAGCCCCAAAGGTTACACAA-3' }\end{array}$ \\
\hline$O s L O X 2$ & Os02g10120 & $\begin{array}{l}\text { F:5'-TACAAGTCCGACGAGGAGGT-3' } \\
\text { R:5'-CCACATGATGGTGGTCAAGA-3' }\end{array}$ \\
\hline OsAOS2 & Os03g12500 & $\begin{array}{l}\text { F:5'-GGAGGAAGCTGCTGCAATAC-3' } \\
\text { R:5'-GTGTCGTACCGGAGGAAGAG-3' }\end{array}$ \\
\hline OsHSP90 & Os09g30412 & $\begin{array}{l}\text { F:5'-CAAGTCGGACCTCGTCAACA-3' } \\
\text { R:5'-TCTCAGCAACAAGGTAGGCG-3' }\end{array}$ \\
\hline OsPR5 & Os $12 \mathrm{~g} 43380$ & $\begin{array}{l}\text { F:5'-CGCTTACCTGTTCCCCGAAG-3' } \\
\text { R:5'-ATGGGCAGAAGACGACTTGG-3' }\end{array}$ \\
\hline actin & Os11g06390 & $\begin{array}{l}\text { F:5'-GAGTATGATGAGTCGGGTCCAG-3' } \\
\text { R:5'-ACACCAACAATCCCAAACAGAG-3 }\end{array}$ \\
\hline
\end{tabular}

included in all experiments testing the effects of SA and $\mathrm{pH}$ on the growth of mycelium, sporulation quantity, spore germination and appressorium formation, disease investigation, and qRT-PCR. All data and statistical analyses were performed in SPSS 13.0. A two-way analysis of variance (ANOVA) was carried out, followed by the Duncan's multiple range tests. Graphs were plotted with Sigmaplot 10.0.

\section{Results}

\section{Effects of SA concentration and pH level on the morphological development of blast strains}

To identify the effects of different concentrations of SA and different $\mathrm{pH}$ values on the morphological development of the BAS1-overexpression strain, we treated plants inoculated with different concentrations of SA and different $\mathrm{pH}$ values (BAS1-overexpression strain and a WT strain of 95234I-1b treated with the same DMSO or sterilized water as controls).

The results showed that there was no significant difference between the different concentrations of SA on the colony growth of the BAS1-overexpressing strain or the WT strain, compared with the control plants of each strain that were pretreated with only DMSO (Fig. 1). This result indicated that SA had no effect on the colony growth of either blast strain.

Colony growth of the BAS1-overexpression strain was lower in the $\mathrm{pH} 5.00$ medium than in the control; however, the difference was not significant. BAS1-overexpression strain cultured in $\mathrm{pH} 8.00$ medium had a significantly higher colony growth than that of the control (Fig. 1). Overall, $\mathrm{pH}$ highly affects the BAS1-overexpression strain comparing to the WT strain.

SA suppressed sporulation in both the BAS1overexpression and WT strains compared with the DMSO control (Fig. 2a). The $50 \mu \mathrm{M}$ SA treatment resulted in greater suppression of sporulation in the BAS1-overexpression strain than in the WT strain, and the $200 \mu \mathrm{M}$ SA suppressed the sporulation of both the BAS1-overexpression strain and the WT strain (Fig. 2a). However, $\mathrm{pH}$ had no significant effects on the sporulation of the BAS1-overexpression strain or the WT strain. However, with the same $\mathrm{pH}$ value, the sporulation of the BAS1-overexpression strain was lower than that of the WT strain (Fig. 2b).

Two hours after SA treatment, spore germination in the 50 and $100 \mu \mathrm{M}$ SA treatments was not significantly different than in the CK treatment, whereas the $150 \mu \mathrm{M}$ SA treatment had significantly less spore germination than $\mathrm{CK}$ in both the BAS1-overexpression and WT strains (Fig. 3a). In the $200 \mu \mathrm{M}$ SA treatment, spore germination was completely suppressed in both blast strains (Fig. 3a). Appressorium formation was observed $6 \mathrm{~h}$ after SA treatment. The 50 and $100 \mu \mathrm{M}$ SA treatments had no suppression of the appressorium formation in either the WT or BAS1-overexpression strains, whereas the $150 \mu \mathrm{M}$ SA treatment began to suppress appressorium formation of both blast strains and the $200 \mu \mathrm{M}$ SA treatment completely suppressed appressorium formation in both strains (Fig. 3b). Different concentrations of SA had a greater effect on suppression of appressorium formation in WT compared with the BAS1-overexpression strain. 

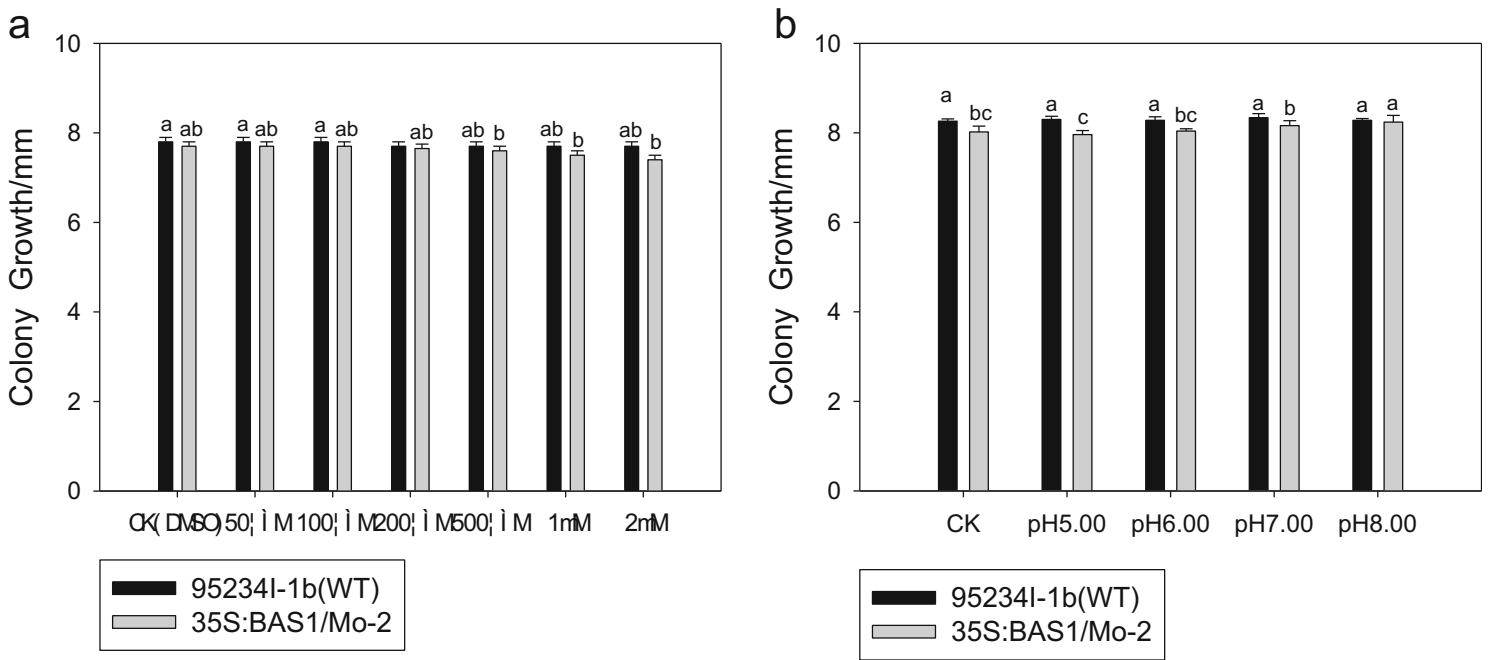

Fig. 1 Effect of different concentrations of salicylic acid (a) and pH (b) on the colony growth of two rice blast strains (Magnaporthe oryzae). Values show the means \pm SD of three biological replicates. Different letters represent significant difference at $P \leq 0.05$ using Duncan's multiple range test

At higher $\mathrm{pH}$ values, there was significantly greater suppression of spore germination in the BAS1-overexpression strain compared with the WT strain (Fig. 4a). In contrast, within each strain, different $\mathrm{pH}$ values had no significant difference in terms of spore germination rate. The appressorium of BAS1-overexpression strain was observed $2 \mathrm{~h}$ after $\mathrm{pH}$ treatment, but appressorium was not observed at $2 \mathrm{~h}$ after spores of the WT strain were treated with $\mathrm{pH}$ 6.00-8.00. Under different $\mathrm{pH}$ conditions, the appressorium formation rate was not significantly different for BAS1-overexpression strain, whereas different $\mathrm{pH}$ values had an effect on suppression of appressorium formation of WT strain (Fig. 4). The different $\mathrm{pH}$ values had no significant effects on the formation rate of appressorium of the BAS1-overexpression strain.

\section{Effects of different concentrations of SA and different pH values on the pathogenicity of blast strains}

We next made an analysis of the pathogenicity of BAS1overexpression isolates under different concentrations of SA and $\mathrm{pH}$. BAS1-overexpression and WT strains were pretreated with $200 \mu \mathrm{M}$ SA and $\mathrm{pH}$ of 5.00 or 8.00 , and disease symptoms were investigated 7 days after the inoculation.

Disease symptoms were less severe in both blast strains pretreated with $200 \mu \mathrm{M}$ SA compared with the CK (Fig. 5, Table 2). The results indicated that the disease symptoms in rice seedlings inoculated with spores of BAS1-overexpression strain and WT strain pretreated with $200 \mu \mathrm{M}$ SA was significantly smaller than that of $\mathrm{CK}$, whereas the decrease of the
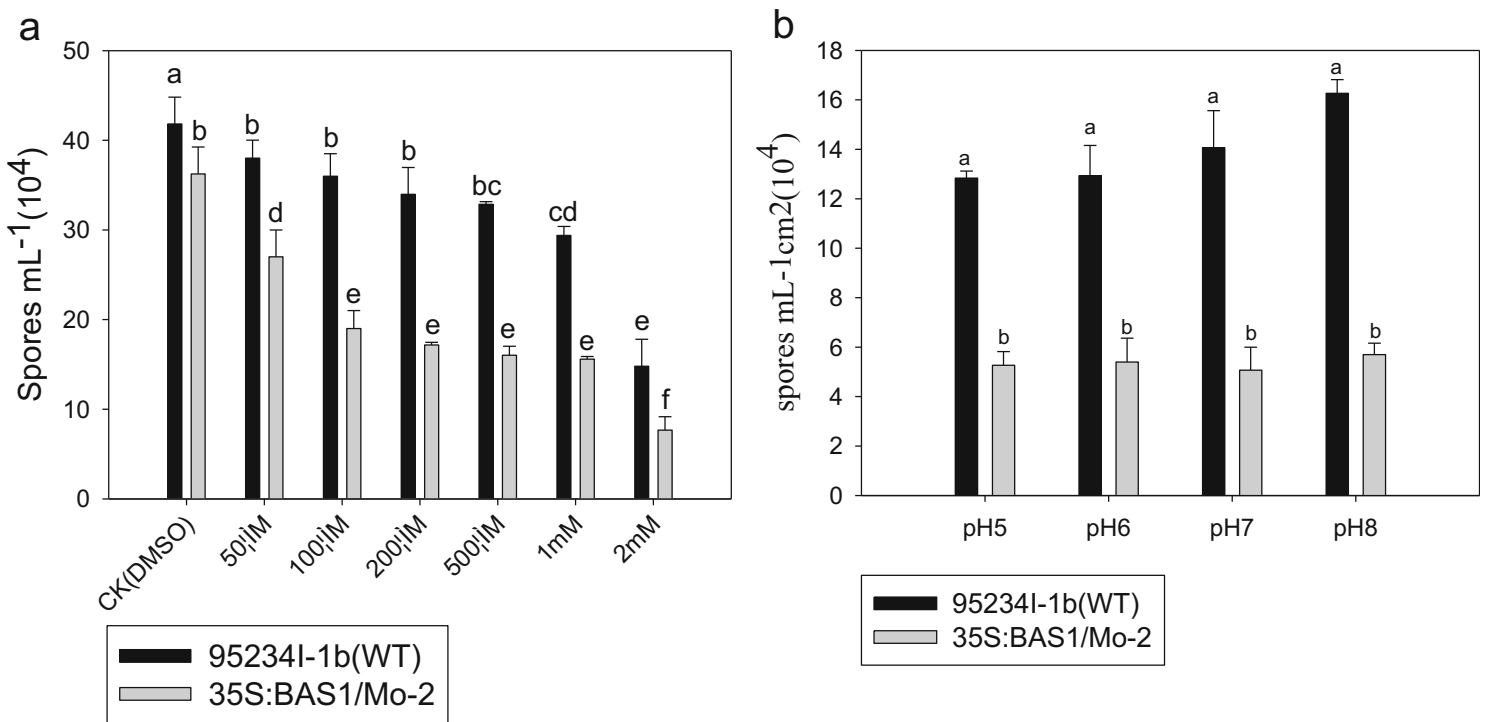

Fig. 2 Effect of salicylic acid concentration and $\mathrm{pH}$ on number of spores in wild-type (WT) and BAS1-overexpression rice blast strains (Magnaporthe oryzae). Values show the means $\pm \mathrm{SD}$ of three biological replicates. Different letters represent significant difference at $P \leq 0.05$ 

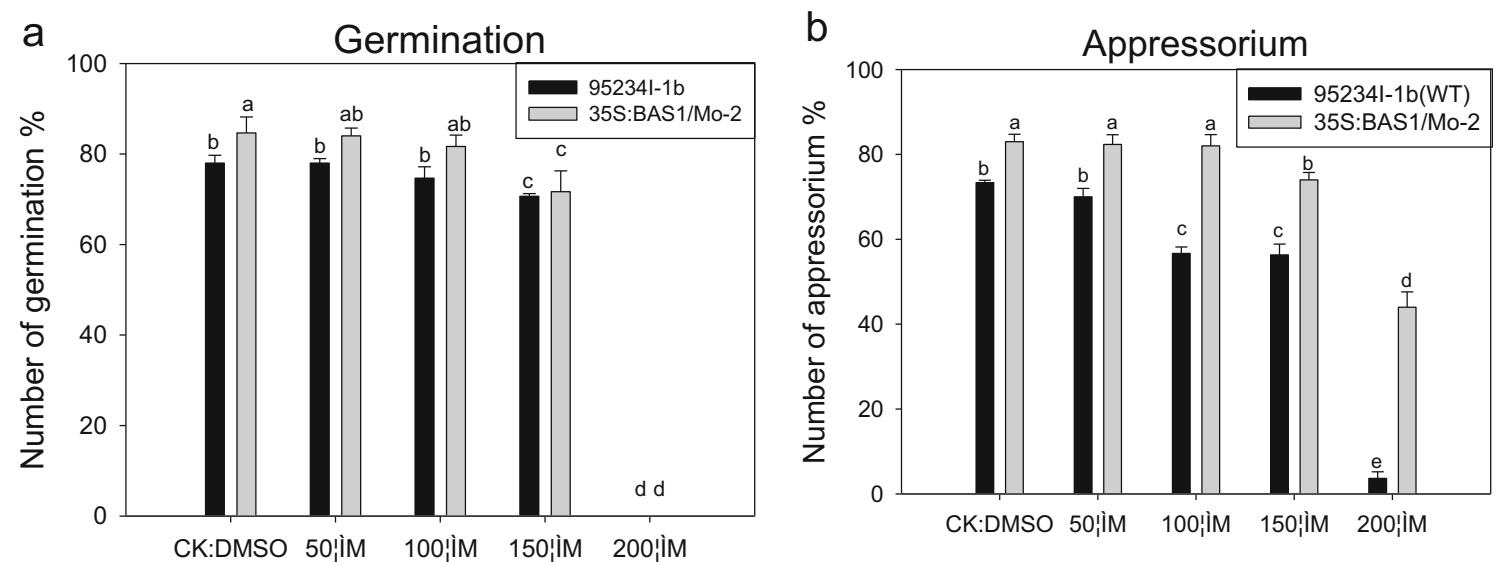

Fig. 3 Effects of different SA concentrations on germination (a) and appressorium (b) of spores in wild-type (WT) and BAS1-overexpression rice blast strains (Magnaporthe oryzae). Values show the means $\pm \mathrm{SD}$ of three biological replicates. Different letters represent significant difference at $P \leq 0.05$

symptom in rice seedling inoculated with BAS1overexpression strain pretreated with $200 \mu \mathrm{M}$ SA was smaller than that of WT strain pretreated with $200 \mu \mathrm{M}$ SA.

The disease symptoms of rice seedlings inoculated with BAS1-overexpression strain pretreated with $\mathrm{pH} 5.00$ and $\mathrm{pH}$ 8.00 were more severe than that of WT strain (Fig. 5). The disease incidence rate in rice leaves inoculated with the spore of the BAS1-overexpression strain pretreated with $\mathrm{pH} 5.00$ was $45.67 \%$ (Table 3 ), which is significantly higher than the $36.6 \%$ in leaves inoculated with WT strain pretreated with the same $\mathrm{pH}$. We observed a higher disease incidence rate in leaves inoculated with the BAS1-overexpression and WT strains pretreated with $\mathrm{pH} 8.00$ than in leaves inoculated with the WT strain pretreated with $\mathrm{pH} 5.00$ (Table 3).

\section{Effects of SA and pH on defense system of rice infected by blast strains}

We analyzed rice defense-related genes, such as PRIa and PR10a, PAL and EDS1,LOX2 and AOS2, and HSP90 and

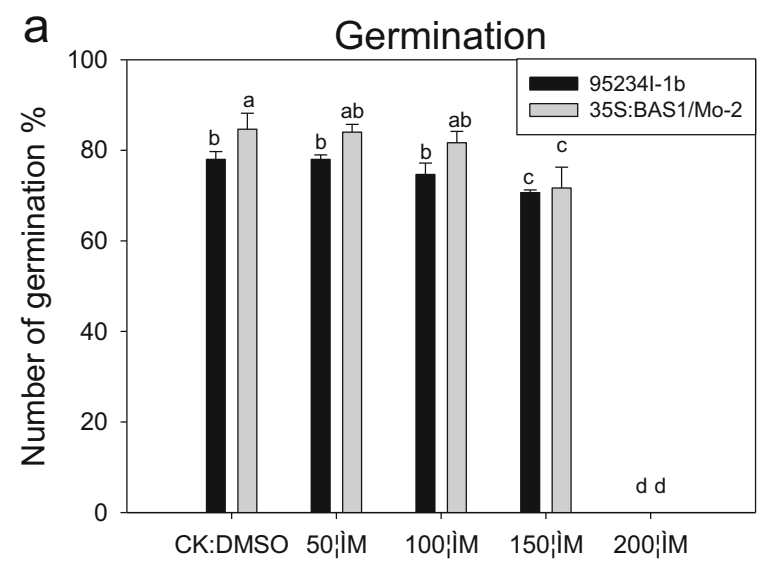

$P R 5$ in leaves inoculated with blast strains pretreated with $200 \mu \mathrm{M}$ SA, $\mathrm{pH} 5.00$ and $\mathrm{pH}$ 8.00. PRI $a$ in leaves inoculated with BAS1-overexpression strain was higher than in leaves inoculated with WT strain in the $200 \mu \mathrm{M}$ SA pretreatment (Fig. 6). The expression of PRIa in leaves inoculated with the BAS1-overexpression strain pretreated with $200 \mu \mathrm{M} \mathrm{SA}$ was higher at 72 and $96 \mathrm{~h}$ post-inoculation (hpi) compared with the other time points studied $(24,48$, and $96 \mathrm{hpi})$, revealing that the expression level of PRIa in leaves inoculated with the BAS1-overexpression strain at the later stage of infection was higher than in the earlier stage. The expression level of PRIa in leaves inoculated with the BAS1-overexpression strain pretreated with $200 \mu \mathrm{M} \mathrm{SA}$ at 48 and 72 hpi was higher than that of leaves inoculated with the WT strain pretreated with $200 \mu \mathrm{M} \mathrm{SA}$, whereas the expression level at 96 and 120 hpi was lower than in leaves inoculated with the WT strain pretreated with $200 \mu \mathrm{M}$ SA (Fig. 6).

The expression level of EDS1 and PAL appeared higher in leaves inoculated with BAS1-overexpression strain than in leaves inoculated with the WT strain when both strains were

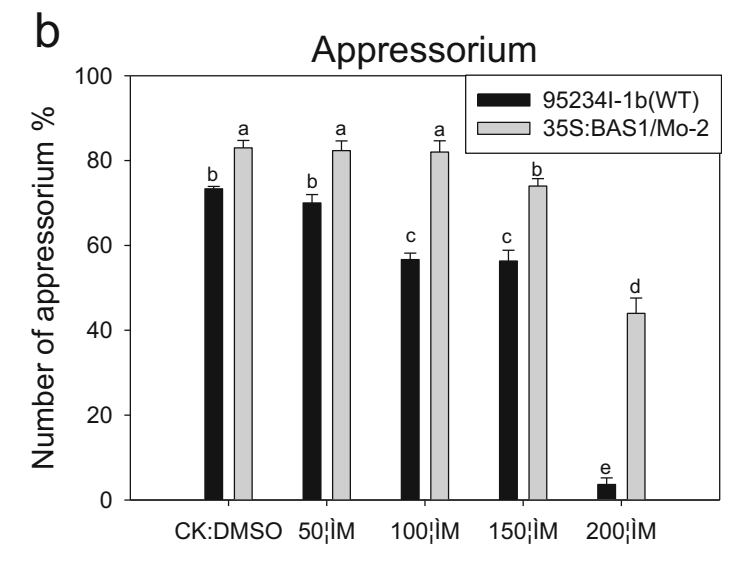

Fig. 4 Effects of $\mathrm{pH}$ on spore germination and appressorium in wild-type (WT) and BAS1-overexpression rice blast strains (Magnaporthe oryzae). Values show the means $\pm \mathrm{SD}$ of three biological replicates. Different letters represent significant difference at $P \leq 0.05$ 
Fig. 5 Symptoms on rice leaves pretreated with $200 \mu \mathrm{M}$ of salicylic acid (a) or $\mathrm{pH} 5.00$ or 8.00 (b) and then inoculated with a wild-type (WT) or BAS1overexpression rice blast strain (Magnaporthe oryzae)
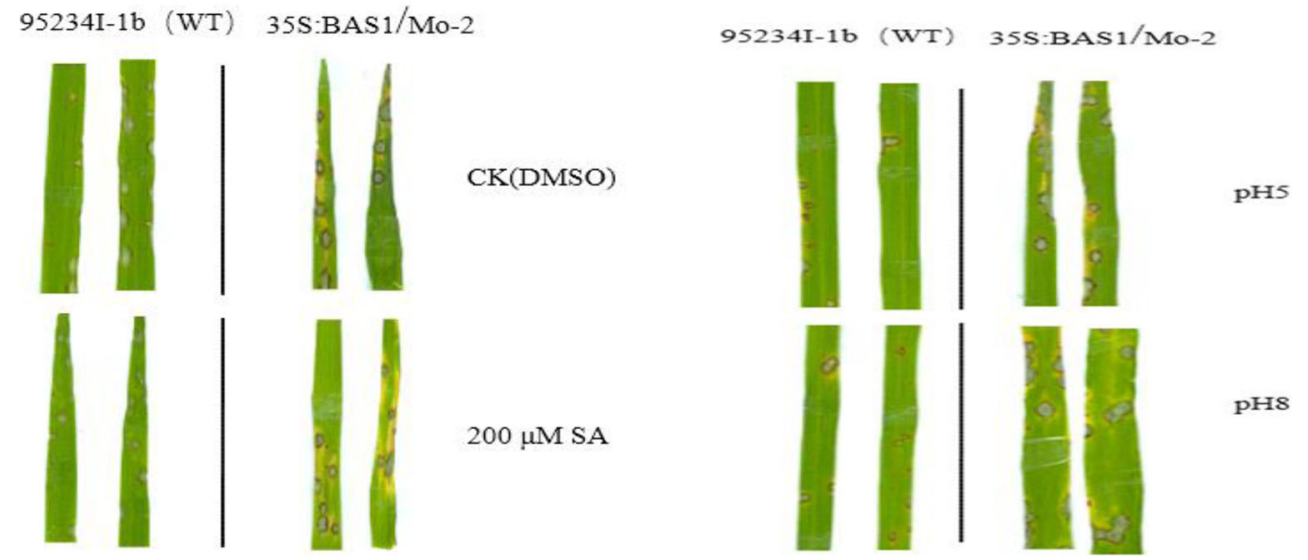

pretreated with $200 \mu \mathrm{M}$ SA during infection. The highest expression level of EDS1 and PAL inoculated in the BAS1overexpression strain pretreated with $200 \mu \mathrm{M} \mathrm{SA}$ at 24 and 96 hpi (Fig. 7).

The expression level of $L O X 2$ in leaves inoculated with the BAS1-overexpression and WT strains pretreated with $200 \mu \mathrm{M}$ SA appeared downregulated during infection, but there was more downregulation in leaves inoculated with the BAS1overexpression strain than in leaves inoculated with the WT strain (Fig. 7). The expression level of AOS2 in leaves inoculated with BAS1-overexpression strain pretreated with $200 \mu \mathrm{M}$ SA appeared a little upregulation during infection comparing with from 24 to $72 \mathrm{hpi}$, and it appeared higher expression level of AOS2 in leaves inoculated with the BAS1-overexpression strain than in leaves inoculated with the WT strain at 96 and 120 hpi (Fig. 7).

In the $200 \mu \mathrm{M}$ SA pretreatments, the expression level of PR5 in leaves inoculated with the BAS1-overexpression strain was higher than in leaves inoculated with WT strain. The expression level of HSP90 in leaves inoculated with the BAS1overexpression strain pretreated with $200 \mu \mathrm{M}$ SA was significantly higher than that of leaves inoculated with WT strain pretreated with the same SA at 24, 48, and 72 hpi (Fig. 8).

The expression levels of PRIa and PR10a in leaves inoculated with BAS1-overexpression strain and pretreated with

Table 2 Disease incidence of spores on rice leaves pretreated with salicylic acid (SA) and inoculated with wild-type (WT) or BAS1overexpression rice blast strains (Magnaporthe oryzae). Values show the means \pm SD of three biological replicates. Different letters represent significant difference at $P \leq 0.05$

\begin{tabular}{lll}
\hline Rice leaves & \multicolumn{2}{l}{ Disease incidence $(\%)$} \\
\cline { 2 - 3 } & $95234 \mathrm{I}-1 \mathrm{~b}(\mathrm{WT})$ & $35 \mathrm{~S}: \mathrm{BAS} 1 / \mathrm{Mo}-2$ \\
\hline $\mathrm{CK}(\mathrm{DMSO})$ & $47.37 \pm 4.71 \mathrm{~b}$ & $55.3 \pm 5.46 \mathrm{a}$ \\
$200 \mu \mathrm{M} \mathrm{SA}$ & $32.07 \pm 2.03 \mathrm{c}$ & $41.83 \pm 0.85 \mathrm{~b}$ \\
\hline
\end{tabular}

pH 5.00 and pH 8.00 were more downregulated than those of leaves inoculated with WT strain pretreated with the two different $\mathrm{pH}$ values during infection (Fig. 9). The expression of PRla was lower in leaves inoculated with the BAS1overexpression strain pretreated with $\mathrm{pH} 8.00$ compared with those pretreated with $\mathrm{pH} 5.00$ (Fig. 9).

The expression level of $P A L$ appeared lower in leaves inoculated with the BAS1-overexpression strain pretreated with $\mathrm{pH} 5.00$ and $\mathrm{pH} 8.00$ than that of leaves inoculated with WT strain pretreated with the two $\mathrm{pH}$ values during infection. Expression levels of EDS1 appeared lower in leaves inoculated with the BAS1-overexpression strain pretreated with $\mathrm{pH}$ 5.00 and $\mathrm{pH} 8.00$ than in leaves inoculated with the WT strain pretreated with the two $\mathrm{pH}$ values. There were lower expression levels of EDSI and PAL in leaves inoculated with the BAS1-overexpression strain pretreated with $\mathrm{pH} 8.00$ than in leaves inoculated with the overexpression strain pretreated with pH 5.00 (Fig. 10).

Expression of $L O X 2$ in leaves inoculated with the BAS1overexpression strain and the WT strain pretreated with $\mathrm{pH}$ 5.00 and $\mathrm{pH} 8.00$ was significantly downregulated during infection, and lower regulation was observed in leaves inoculated with the BAS1-overexpression strain pretreated with both $\mathrm{pH}$ values. The expression quantity of AOS2 in rice seedlings inoculated by spores of overexpression isolates treated under

Table 3 Disease incidence in rice leaves pretreated with $\mathrm{pH} 5.00$ or $\mathrm{pH}$ 8.00 and inoculated with a wild-type strain (WT) or BAS1overexpression strain (35S:BAS1/Mo-2) of rice blast. Values show the means \pm SD of three biological replicates. Different letters represent significant difference at $P \leq 0.05$

\begin{tabular}{lll}
\hline Rice leaves & \multicolumn{2}{l}{ Disease incidence $(\%)$} \\
\cline { 2 - 3 } & $95234 \mathrm{I}-1 \mathrm{~b}(\mathrm{WT})$ & $35 \mathrm{~S}: \mathrm{BAS} 1 / \mathrm{Mo}-2$ \\
\hline pH 5.00 & $36.6 \pm 5.7 \mathrm{~b}$ & $45.67 \pm 2.84 \mathrm{a}$ \\
$\mathrm{pH} 8.00$ & $43.93 \pm 2.29 \mathrm{a}$ & $46.97 \pm 1.32 \mathrm{a}$ \\
\hline
\end{tabular}



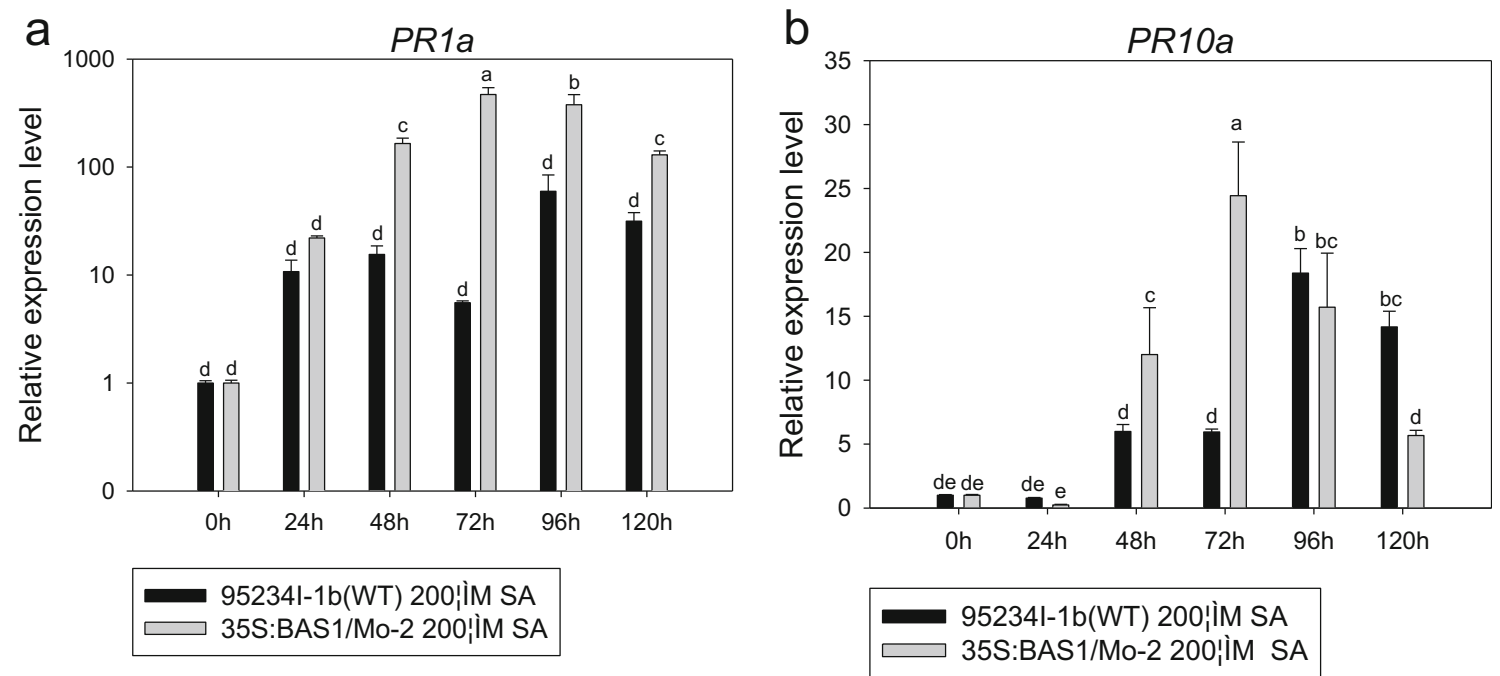

Fig. 6 The expression level of PRI $a$ and PR10a in leaves inoculated with BAS1-overexpression strain pretreated with $200 \mu \mathrm{M}$. Values show the means $\pm \mathrm{SD}$ of three biological replicates. Different letters represent significant difference at $P \leq 0.05$
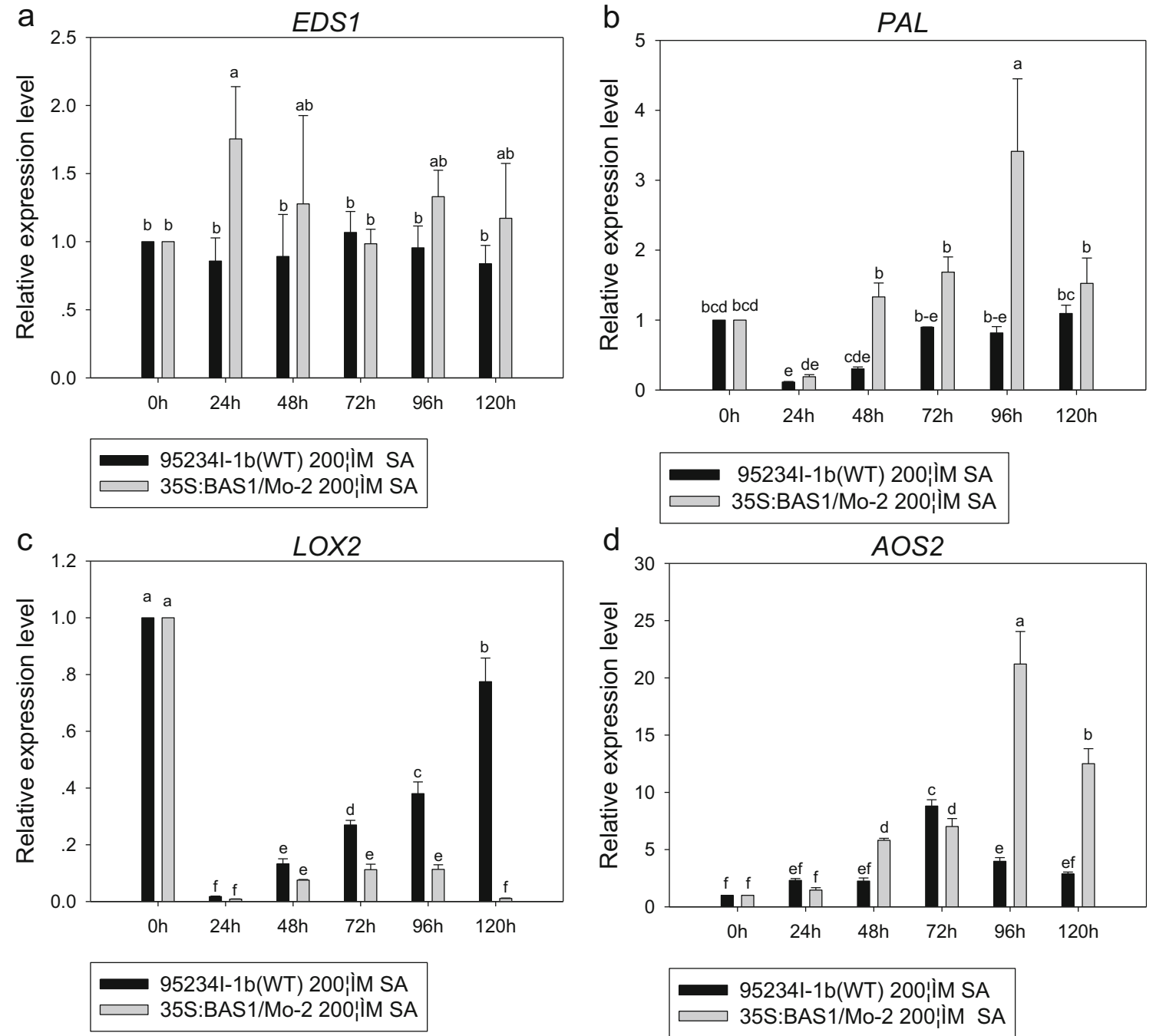

Fig. 7 The expression level of EDS1, PAL, LOX2, and AOS2 in leaves inoculated with BAS1-overexpression strain pretreated with $200 \mu \mathrm{M}$. Values show the means $\pm \mathrm{SD}$ of three biological replicates. Different letters represent significant difference at $P \leq 0.05$ 

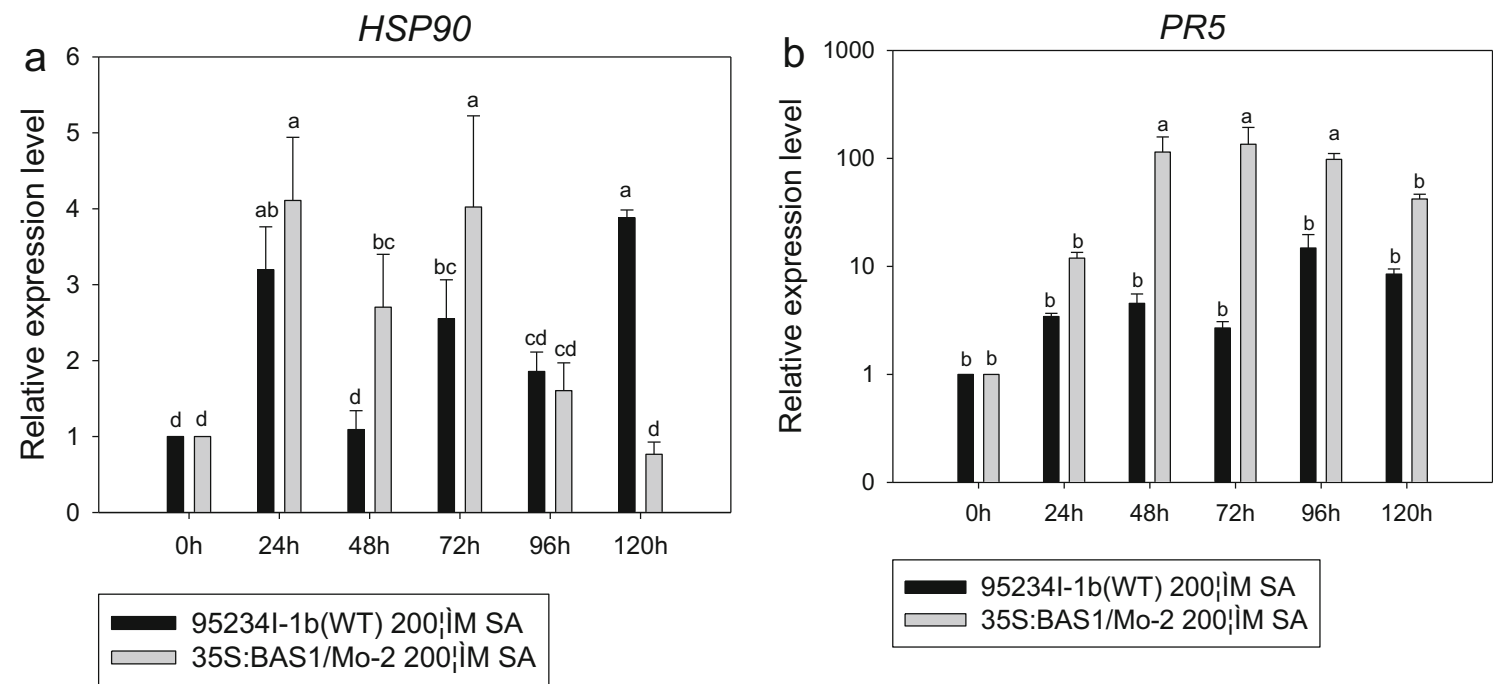

Fig. 8 The expression level of $P R 5$ and $H S P 90$ in leaves inoculated with BAS1-overexpression strain pretreated with $200 \mu \mathrm{M}$. Values show the means \pm $\mathrm{SD}$ of three biological replicates. Different letters represent significant difference at $P \leq 0.05$

pH 5.00 and $\mathrm{pH} 8.00$ was significantly upregulated during infection (Fig. 10).

The expression level of HSP90 in leaves inoculated with the BAS1-overexpression strain pretreated with $\mathrm{pH} 5.00$ was significantly upregulated at $24 \mathrm{hpi}$. The expression level of HSP90 in leaves inoculated with the BAS1-overexpression strain pretreated with $\mathrm{pH} 8.00$ was higher than in leaves inoculated with the BAS1-overexpression strain pretreated with $\mathrm{pH}$ 5.00. The relative expression level of PR5 in the BAS1overexpression strain pretreated with $\mathrm{pH} 5.00$ and $\mathrm{pH} 8.00$ was upregulated during infection. However, the relative expression level of $P R 5$ in leaves inoculated with the WT strain pretreated with $\mathrm{pH} 5.00$ was higher than that of leaves inoculated with BAS1-overexpression strain pretreated with $\mathrm{pH}$ 5.00 (Fig. 11).

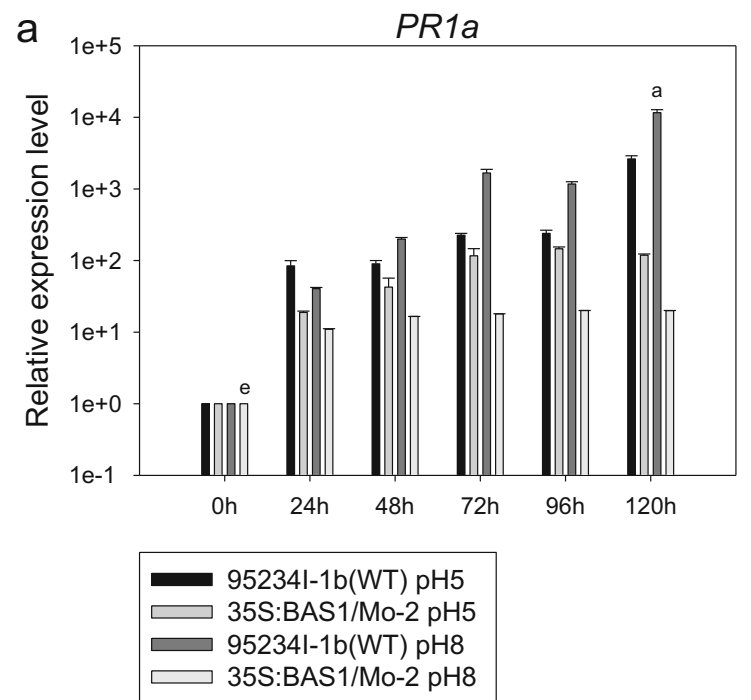

\section{Discussion}

Climate change could create the environmental conditions for a disease triangle (host plant, pathogen, and environmental conditions suitable for disease development) and this could intensify the occurrence of epidemic plant diseases (Mcelrone et al. 2007). Changes in environment conditions can have a direct impact on pathogens and host plants. During the interaction between M. oryzae and rice, M. oryzae secretes effector proteins to regulate and manage the cellular structure and physiological metabolism process of rice before infecting the host.

By analyzing the effects of different $\mathrm{pH}$ values on the morphological development of blast strains, we found that different $\mathrm{pH}$ values had certain effects on the colony growth, spore germination, and other aspects of blast strains; however, it

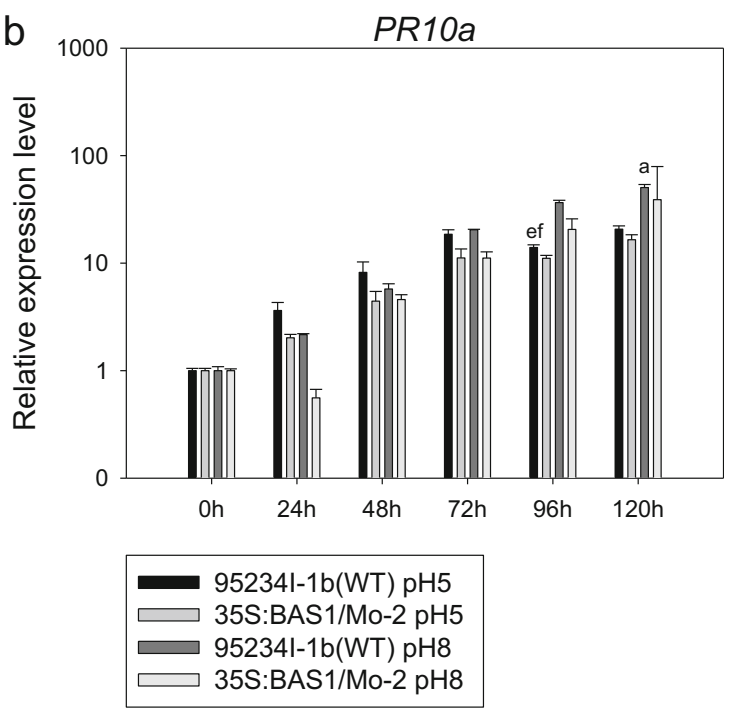

Fig. 9 The expression level of PRIa and PR1Oa in leaves inoculated with BAS1-overexpression strain pretreated with $\mathrm{pH} 5.00$ and $\mathrm{pH} 8.00$. Values show the means $\pm \mathrm{SD}$ of three biological replicates. Different letters represent significant difference at $P \leq 0.05$ 

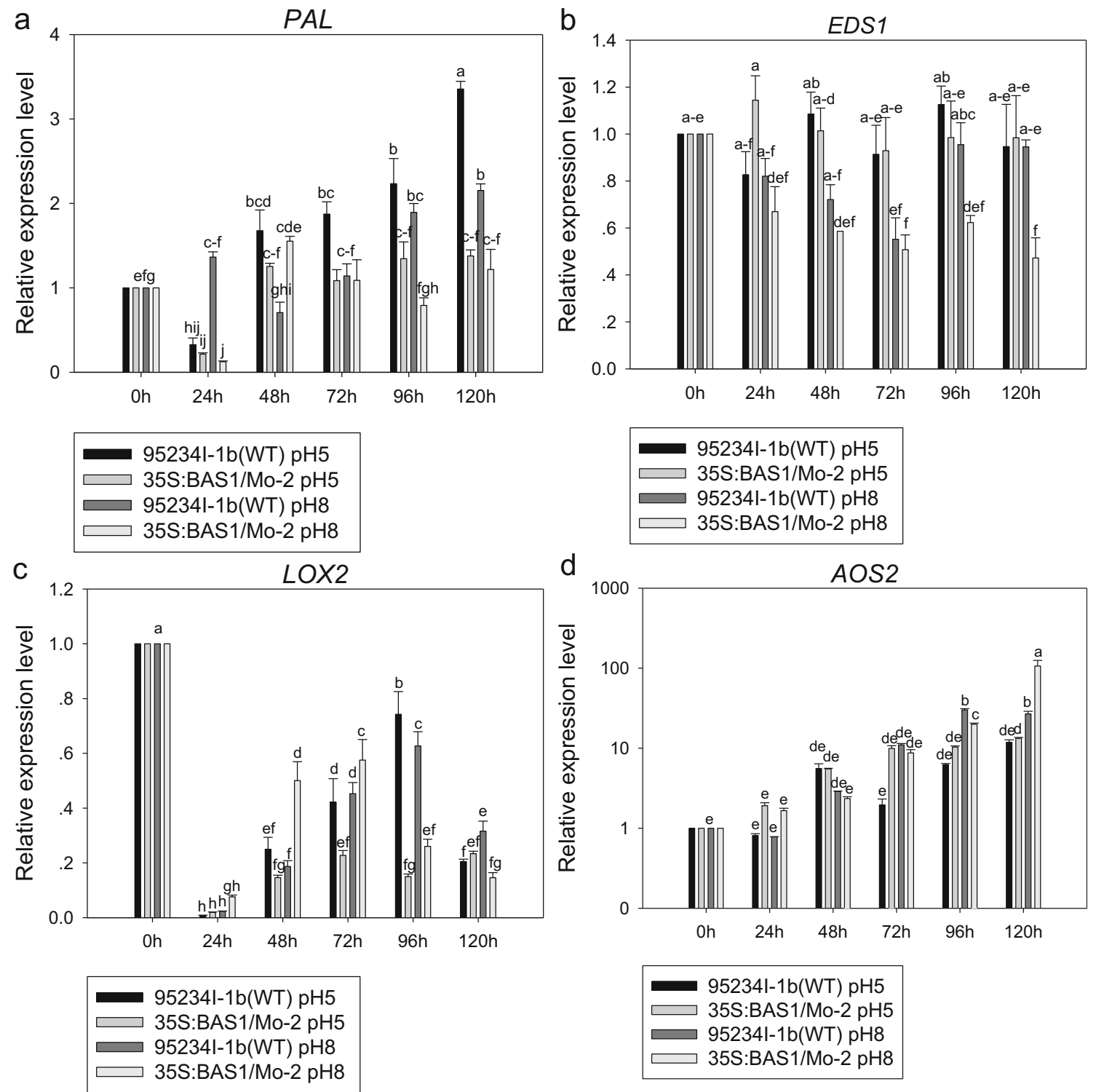

Fig. 10 The expression level of PAL, EDS1, LOX2, and AOS2 in rice leaves inoculated with a BAS1-overexpression strain pretreated with $\mathrm{pH} 5.00$ and $\mathrm{pH}$ 8.00. Values show the means $\pm \mathrm{SD}$ of three biological replicates. Different letters represent significant difference at $P \leq 0.05$

appeared there was no significant effect on the colony growth of WT strains. Landraud et al. (2013) found that the M. oryzae strain Guy11 cultured in PDA (potato dextrose agar) medium with $\mathrm{pH}$ between 5.00 and 8.00 experienced no significant differences in colony growth. Trushina et al. (2013) also found that the deletion mutant $\Delta$ pacC of the Trichoderma transcription factor PacC grew at a slow rate in alkaline PDA. Effector proteins have certain acid-base properties, and they can change the acid-base properties of their microenvironment after secreting the effectors, which can promote or suppress the growth of the pathogens. The effect of different $\mathrm{pH}$ levels on mycelia growth of several species of dematiaceous fungi (Chai and Liu 2010) and the influence of low pH on arbuscule development, and inhibition effect has been shown to increase (Feng et al. 2017).
We also found that different $\mathrm{pH}$ values had an influence on the morphological development of the BAS1-overexpression strain, and that different $\mathrm{pH}$ levels could increase the disease incidence rate in rice infected by overexpression isolates. Zou et al. (2010) reported that the function of a few cells is controlled by $\mathrm{pH}$, but the function of these cells was related to pathogen-infecting plants. In this paper, we found some genes appeared upregulated and others downregulated. The expression level of the pathogenesis-related genes PRIa and PR10a decreased in leaves inoculated with the overexpression strain pretreated with the two $\mathrm{pH}$ values. It is well known that the PRIa gene is related to the PCD (programmed cell death) signal pathway, and its high expression level promotes the death of a large number of cells in an infected rice seedling and thus suppresses further infection by pathogens (Wu et al. 2014; 

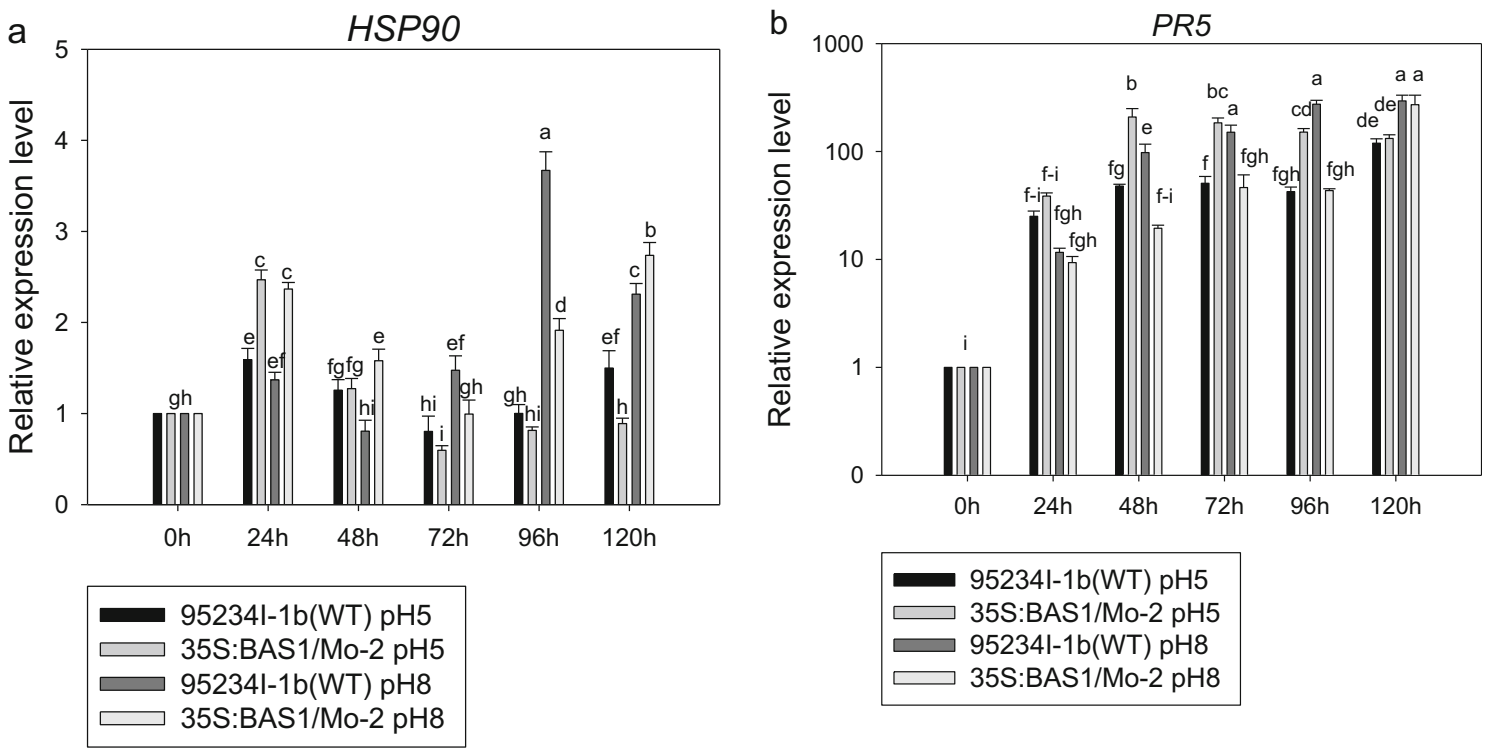

Fig. 11 The expression levels of $H S P 90$ and $P R 5$ in leaves inoculated with BAS1-overexpression strain pretreated with $\mathrm{pH} 5.00$ and $\mathrm{pH} 8.00$. Values show the means $\pm \mathrm{SD}$ of three biological replicates. Different letters represent significant difference at $P \leq 0.05$

Fekih et al. 2015). However, in this study, the expression level of PRIa decreased, indicating that the death of the rice cells was suppressed, and this facilitated further infection of the overexpression strain. Concurrently, we found that the expression level of $L O X 2$ and the $P A L$ also decreased, indicating that the JA and SA signal pathways of the infected rice seedlings were suppressed, i.e., the defense response of the infected rice seedlings was also suppressed.

Heat shock protein 90 (HSP90) is one of the most broadly studied proteins in HSP families. It functions in cells as a molecular chaperone in response to stress conditions (Yan et al. 2017). We found that the expression level of $H S P 90$ was upregulated at $24 \mathrm{hpi}$ in leaves inoculated with the overexpression strain and, since $H S P 90$ is a stress response gene, the upregulated expression of this gene indicated that the infected rice seedlings were under stress response instead of defense response. In the infected rice seedlings, the upregulation of HSP90 together with the decrease of expression level of PRIa promoted the infection and colonization of the overexpression strain.

SA is a metabolite produced in the plant infected by the pathogens by itself and is bound to affect the morphological development of the pathogens to different degrees. SA could induce enzymatic antioxidant activities, related gene expression such as PRI $a$ and PR1Oa (Xie et al. 2011; Gill et al. 2016; Kanno et al. 2012), and heat shock protein 90 (HSP90) was one of the most broadly studied proteins in HSP families. It functioned in cells as molecular chaperones in response to stress conditions (Yan et al. 2017). Pathogenesis-related proteins-1 (PR-1), glucanase (Glu), and chitinase (Chi) genes are widely considered is a defensive gene for SA-dependent signaling pathways (Glazebrook 1999).
We found that different concentrations of SA had certain effects on the morphological development of the BAS1overexpression strain, and we also found a significant decrease in disease incidence rate, and the expression level of $P R 1 a$ and $P R 10 a$ in leaves infected by rice blast strain pretreated with $200 \mu \mathrm{M}$ SA. These effects appeared to be greatest at the early stages of infection and gradually decrease in the later stages of infection, indicating that SA induces an early defense response in infected rice plants and that the death of rice cells was suppressed at the late stage of infection. PRIa is a gene related to the PCD signal pathway, and its expression promotes the death of a large number of cells in an infected rice seedling and thus inhibits further infection of the pathogens (Wu et al. 2014; Fekih et al. 2015). SA plays a key role in the signal transduction path of plant response to biotic stress (Horváth et al. 2007), and the expression of the stress response gene HSP90 in leaves infected by the overexpression isolates pretreated with $200 \mu \mathrm{M}$ SA was upregulated at $24 \mathrm{~h}$, indicating that the infected rice seedlings were under significant stress response at the time. In addition, we found that the expression of the $P A L$ gene gradually increased over time, indicating that exogenous SA induced the SA signal pathway of the infected rice seedlings. So the BAS1-overexpression strain had higher tolerance to abiotic stress than WT strain. Zhang et al. (2015) found that the expression of the CRN effector protein PsCRN115 of Phytophthora sojae in the Nicotiana benthamiana improved the resistance of $N$. benthamiana to biotic stress and abiotic stress. Therefore, it can be seen that the expression of pathogen effector proteins in either plants or the pathogens helps improve their tolerance to the external biotic stress and abiotic stress. 
Author contributions JY, YW, LL, LL, and CW carried out the experiment work. JY and CL helped in drafting the paper and interpreting the data. All authors read and approved the final manuscript.

Funding This work was supported by the National Key R\&D Program of China (2017YFD0200400), the National Natural Science Foundation of China (Grant No. 31400073), and the Yunnan Natural Science foundation (Grant No. 2013FB039) from the Yunnan Science and Technology Department of China.

Open Access This article is distributed under the terms of the Creative Commons Attribution 4.0 International License (http:// creativecommons.org/licenses/by/4.0/), which permits unrestricted use, distribution, and reproduction in any medium, provided you give appropriate credit to the original author(s) and the source, provide a link to the Creative Commons license, and indicate if changes were made.

\section{References}

Alkan N, Espeso EA, Prusk D (2013) Virulence regulation of phytopathogenic fungi by $\mathrm{pH}$. Antioxid Redox Signal 19:1012-1025

Białas A, Zess EK, De JLC, Franceschetti M, Pennington HG, Yoshida K et al (2017) Lessons in effector and nlr biology of plant-microbe systems. Mol Plant Microbe Interact. MPMI08170196FI

Chai B, Liu WD (2010) Effection of different $\mathrm{pH}$ on the growth of several species of Dematiaceous fungi. J Trop Med 10:815-816

Cooper B, Campbell KB, Beard HS, Garrett WM, Islam N (2016) Putative rust fungal effector proteins in infected bean and soybean leaves. Phytopathology 106:491-499

Fekih R, Tamiru M, Kanzaki H, Abe A, Yoshida K, Kanzaki E, Saitoh H, Takagi H, Natsume S, Undan JR, Undan J, Terauchi R (2015) The rice (oryza sativa 1.) lesion mimic resembling, which encodes an aaatype atpase, is implicated in defense response. Mol Genet Genomics 290:611-622

Feng ZW, Wang N, Zhu HH, Yao Q (2017) Influences of low pH on the arbuscule development and phosphorus uptake of Rhizophagus intraradices. Mycosystema 36:950-962

Gao S, Liu T, Li Y, Wu Q, Fu K, Chen J (2012) Understanding resistant germplasm-induced virulence variation through analysis of proteomics and suppression subtractive hybridization in a maize pathogen Curvularia lunata. Proteomics 12:3524-3535. https://doi.org/10. 1002/pmic.201200105

Gebauer P, Korn M, Engelsdorf T, Sonnewald U, Koch C, Voll LM. (2017). Sugar Accumulation in Leaves of Arabidopsissweet11/ sweet12Double Mutants Enhances Priming of the Salicylic AcidMediated Defense Response. Front Plant Sci 8:1378

Gill RA, Zhang N, Ali B, Farooq MA, Xu J, Gill MB, Mao B, Zhou W (2016) Role of exogenous salicylic acid in regulating physiomorphic and molecular changes under chromium toxicity in blackand yellow- seeded Brassica napus L. Environ Sci Pollut Res 23: 20483-20496

Glazebrook J (1999) Genes controlling expression of defense responses in Arabidopsis. Curr Opin Plant Biol 2:280-286

Gumtow R, Wu D, Uchida J, Tian M (2017) A phytophthora palmivora extracellular cystatin-like protease inhibitor targets papain to contribute to virulence on papaya. Mol Plant-Microbe Interact 31:363373

Hogenhout SA, Ra VDH, Terauchi R, Kamoun S (2009) Emerging concepts in effector biology of plant-associated organisms. Mol Plant Microbe Interact 22:115-122. https://doi.org/10.1101/sqb.2012.77. 015933

Horváth E, Szalai G, Janda T (2007) Induction of abiotic stress tolerance by salicylic acid signaling. J Plant Growth Regul 26:290-300
Howard RJ, Ferrari MA, Roach DH, Money NP (1991) Penetration of hard substrates by a fungus employing enormous turgor pressures. PNAS 88:11281-11284

Jong JCD, Mccormack BJ, Smirnoff N, Talbot NJ (1997) Glycerol generates turgor in rice blast. Nature 389(6648):244-244. https://doi. org/10.1038/38418

Kamoun S (2006) A catalogue of the effector secretome of plant pathogenic oomycetes. Annu Rev Phytopathol 44(1):41-60. https://doi. org/10.1146/annurev.phyto.44.070505.143436

Kanno H, Hasegawa M, Kodama O (2012) Accumulation of salicylic acid, jasmonic acid and phytoalexins in rice, Oryza sativa, infested by the white-backed planthopper,Sogatella furcifera (Hemiptera: Delphacidae). Appl Entomol Zool 47:27-34

Kaverinathan K, Scindiya M, Malathi P, Viswanathan R, Sundar AR (2017) Role of melanin in colletotrichum falcatum, pathogenesis causing sugarcane red rot. Sugar Tech 19:1-8

Landraud P, Chuzeville S, Billon-Grande G, Poussereau N, Bruel C (2013) Adaptation to $\mathrm{pH}$ and role of $\mathrm{PacC}$ in the rice blast fungus magnaporthe oryzae. PLoS One 8:e69236. https://doi.org/10.1371/ journal.pone.0069236

Li B, Wang W, Zong Y, Qin G, Tian S (2012) Exploring pathogenic mechanisms of botrytis cinerea secretome under different ambient ph based on comparative proteomic analysis. J Proteome Res 11: 4249-4260. https://doi.org/10.1021/pr300365f

Livak KJ, Schmittgen TD (2001) Analysis of relative gene expression data using real-time quantitative PCR and the 2 (-Delta Delta C (T) ) Method. Methods 25:402-408

Louis B, Waikhom SD, Roy P, Bhardwaj PK, Singh MW, Goyari S, Sharma CK, Talukdar NC (2014) Secretome weaponries of cochliobolus lunatus interacting with potato leaf at different temperature regimes reveal a cl[xxxx]lhm-motif. BMC Genomics 15:213. https://doi.org/10.1186/s12864-015-1337-3

Marce S, Sawers R, Oakeley E, Angliker H, Paszkowski U (2010) Tissueadapted invasion strategies of the rice blast fungus magnaporthe oryzae. Plant Cell 22:3177-3187 http://www.plantcell.org/cgi/doi/ $10.1105 /$ tpc. 110.078048

Mcelrone AJ, Sherald JL, Forseth IN (2007) Effects of water stress on symptomatology and growth of Parthenocissus quinquefolia infected by Xylella fastidiosa. Plant Dis 85:1160-1164

Mitsuhara I, Iwai T, Seo S, Yanagawa Y, Kawahigasi H, Hirose S, Ohkawa Y, Ohashi Y (2008) Characteristic expression of twelve rice PR1 family genes in response to pathogen infection, wounding, and defense-related signal compounds (121/180). Mol Gen Genomics 279:415-427

Pen Y, Chen X, Yang J, Xue M, Wang D, Huang J, Peng Z, Xu J (2011) PacC mediated adaptation to alkaline $\mathrm{pH}$ is critical for developing infection hyphae in penetrated plant cells in Magnaporthe oryzae. Phytopathology 101:S140-S140

Piccirillo S, White MG, Murphy JC, Law DJ, Honigberg SM (2010) The rim $101 \mathrm{p} /$ pacc pathway and alkaline ph regulate pattern formation in yeast colonies. Genetics 184:707-716

Ridout C, Skamnioti P, Porritt O, Sacristan SJ, Brown J (2006) Multiple avirulence paralogues in cereal powdery mildew fungi may contribute to parasite fitness and defeat of plant resistance. Plant Cell 18: 2402-2414. https://doi.org/10.1105/tpc.106.043307

Sharma M, Sengupta A, Ghosh R, Agarwal G, Tarafdar A, Nagavardhini A, Pande S, Varshney RK (2016) Genome wide transcriptome profiling of fusarium oxysporum $\mathrm{f} s \mathrm{~s}$. ciceris conidial germination reveals new insights into infection-related genes. Sci Rep 6:37353

Trushina N, Levin M, Mukherjee PK, Horwitz BA (2013) Pacc and pHdependent transcriptome of the mycotrophic fungus trichoderma virens. BMC Genomics 14:138 http://www.biomedcentral.com/ $1471-2164 / 14 / 138$

Wu L, Chen H, Curtis C, Fu ZQ (2014) Go in for the kill: how plants deploy effector-triggered immunity to combat pathogens. Virulence 5:710-721 
Xie X, Xue Y, Zhou J, Zhang B, Chang H, Takano M (2011) Phytochromes regulate SA and JA signaling pathways in rice and are required for developmentally controlled resistance to Magnaporthe grisea. Mol Plant 4:688-696

Xu S, Chen J, Liu L, Wang X, Huang X, Zhai Y (2007) Proteomics associated with virulence differentiation of curvularia lunata in maize in China. Acta Bot Sin 49:487-496

Yan J, Liang X, Zhang Y, Li Y, Cao X, Gao J (2017) Cloning of three heat shock protein genes (HSP70, HSP90 $\alpha$ and HSP90 $\beta$ ) and their expressions in response to thermal stress in loach (Misgurnus anguillicaudatus) fed with different levels of vitamin C. Fish Shellfish Immunol 66:103-111

Zhang M, Ahmed Rajput N, Shen D, Sun P, Zeng W, Liu T, Juma Mafurah J, Dou D (2015) A Phytophthora sojae cytoplasmic effector mediates disease resistance and abiotic stress tolerance in Nicotiana benthamiana. Sci Rep 5:10837. https://doi.org/10. $1038 /$ srep 10837

Zou CG, Tu HH, Liu XY, Tao N, Zhang KQ (2010) PacC in the nematophagous fungus Clonostachys rosea controls virulence to nematodes. Environ Microbiol 12:1868-1877 